\title{
CLINICAL STUDY ON RABIES PRONE ANIMAL BITE
}

\author{
MOHAMMAD MAHFUZUL HOQUE ${ }^{1}$, FARHANA AKTER ${ }^{2}$, BUM WAHID AHMED ${ }^{3}$, SHEIKH MOHAMMAD \\ NOOR- E-ALAM ${ }^{4}$, ROBED AMIN ${ }^{5}, \mathrm{M} \mathrm{A} \mathrm{FAIZ}^{6}$
}

\begin{abstract}
Introduction: Rabies is almost invariably fatal zoonotic disease, it can be prevent well with proper management of wound and rabies prophylaxis. This study aims to describe the pattern of rabies prone animal bite, to observe the trends of management and relationship with socioeconomic condition of victims.
\end{abstract}

Method : This is an observational study. Data was collected from patients presenting with animal bite or attendants on structured case record form at Infectious Disease Hospital, Dhaka and emergency department of Mitford Hospital from $1^{\text {st }}$ to $27^{\text {th }}$ February 2010. Patients with category II \&III bite were followed up 3 months over phone to observe the outcome.

Results: A total 235 animal bite victims attending at Infectious Disease Hospital and Mitford Hospital were enrolled in study. Young patients, around $49.79 \%$ population within 18 years age group; male $(82.98 \%)$ was more affected and mostly from low socioeconomic condition. Dog bite (91.06\%) was predominant by stray dogs $(94.89 \%)$ Exposure was mainly bite $(83.82 \%)$, which were unprovoked $(95.75 \%)$ and category - $\operatorname{III}(86.81 \%)$. Local wound care was minimal (wash with soap - 28.93\%) and use of nerve tissue and cell culture vaccination was $81.70 \%$ and $18.29 \%$ respectively.

Conclusion : Predominant rabies prone animal bite is stray dog. Victims after bite took ineffective nerve tissue vaccine while missing important rabies immunoglobulin due to economic constraints. The prevention of animal bite need to be addressed for prevention of rabies in Bangladesh.

Key Word: Animal bite, Dog Bite, Rabies

Received: 01 August 2017

Accepted: 28 November 2017

DOI: http://dx.doi.org/10.3329/bjmed.v29i1.35404

\section{Introduction:}

Rabies is a fatal zoonotic viral disease transmitted to human through bite or scratch by infected animal both domestic and wild. Globally, rabies is the tenth leading cause of death due to infection in human and the threat of rabies exists in most part of the world $^{1}$. Predominantly rabies affects poor people in developing countries and for poor quality of rabies reporting, its true incidence is always underestimated. Human mortalities from endemic canine rabies was estimated to be 55,000 deaths per year with $56 \%$ of deaths estimated to occur in Asia and 44\% in Africa. Accurate statistics are not available, however scattered hospital records indicate that about 2000 people die from rabies each year in Bangladesh. ${ }^{2}$
Entry of rabies virus occurs through transdermal bite, scratch or contamination of mucous membrane with saliva (category - III), minor scratch or abrasion without bleeding (category - II) by rabies prone animal. ${ }^{3}$ In Bangladesh the predominant animal observed for potential rabies is dog. Beside these cat, canine wild animals are responsible for less frequent cases while Bats were not found to be responsible in Bangladesh. Its incubation period varies from 2 weeks to 6 year (average 2-3 months) depending on amount of virus in the inoculum site and site of inoculum. The virus moves within peripheral nerve to central nervous system (CNS) by fast retrograde axoplasmic flow. It rapidly spread throughout grey matter. Virus also spread centrifugally

1. Junior Consultant (Medicine), Dhaka Medical College

2. Assistant Professor of Endocrinology, Chittagong Medical College

3. Registrar of Medicine, Dhaka Medical College

4. Assistant Professor of Hepatology, BSMMU

5. Associate Professor of Medicine, Dhaka Medical College

6. Professor of Medicine( Retd) Dhaka Medical College

Address of Correspondence: Dr. Mohammad Mahfuzul Hoque, Junior Consultant (Medicine), Dhaka Medical College, Dhaka

Bangladesh J Medicine 2018; 29 : 26-30 
through nerve to salivary gland, liver, muscle, skin etc. First clinical symptom is usually neuropathic pain at wound site. Two presentations are observed: furious and paralytic forms that cannot be correlated with any specific anatomical localization of rabies in the $\mathrm{CNS}^{4}$. Without intensive care, death occurs within few days (1-5 days) of development of neurological signs. Rabies is inevitably fatal.

Human rabies is suspected, a case that compatible with clinical case definition. To be a confirmed case, laboratory confirmation is done by detection of rabies viral antigen by Direct Fluorescent Antibody test (FAT) or by ELISA from clinical specimen (ante mortem or postmortem) or detection of rabies neutralizing antibody titre in the serum or the CSF of an unvaccinated person or detection of viral nucleocapsid by PCR from clinical specimen. ${ }^{5}$ The confirmatory facilities for human rabies is not routinely available in Bangladesh

Since there is no effective therapy, prevention of disease after animal exposure is extremely important which includes local wound care, passive and active immunization. All bite wounds and scratches are immediately washed thoroughly with soap and water or water only followed by disinfection with ethanol or iodine solution. Dog bite related infections are polymicrobial, predom-inantly Pasteurella Multocida and Bacteroidess pp. Infected bites presenting less than 12 hours after injury are particu-larly likely to be infected with Pasteurella spp, whereas those presenting more than 24 hours after the event are likely to be predominantly infected with staphylococci or anaerobes. Suturing is postponed; tetanus prophylaxis, antibiotic treatment is given whenever indicated and co-amoxiclav is first choice of prophylaxis $^{6}$. In case of category III exposure Immunoglobin (RIG) is regarded as mandatory. Rabies immunoglobin is infiltrated around the wound and residual immunoglobin solution is injected intramuscularly. ${ }^{3}$

For post exposure prophylaxis WHO strongly advocates the use of modern (purified products prepared on cell culture) vaccines that comply with WHO criteria for potency, inequity and have been well designed field trial. WHO supported the trend to abandon completely the production of brain tissue vaccines.Economical rabies PEP regimens using 2, 4 or 8 initial ID sites are as immunogenic as the standard IM regimen, but they use $60 \%$ less vaccine ${ }^{7}$. In addition to standard intramuscular schedules for modern vaccine there are intradermal schedules in which considerable less amount of vaccines is required where vaccine or money is in short supply. ${ }^{3}$

Government of Bangladesh has had strategic plan for rabies prevention and control in Bangladesh and there is guideline rabies prophylaxis and application of intradermal vaccine since $2010^{8,9}$. Under W.H.O guidance South Asian countries are now working on elimination of rabies by the year $2020^{10}$. Successful elimination rabies comprises of two basic components, control of animal rabies and control of human rabies. Mass dog vaccination and management of dog population have long been recognized as the mainstay of successful dog rabies control and eventual elimination $^{1}$.

In rural area of Bangladesh only about $65 \%$ had awareness about the disease of rabies and about $71 \%$ were knowledge about rabies medication ${ }^{11}$. Poverty, lack of education, social prejudice etc. lead to improper management of rabies prone animal bite. There has not been ample study on animal bite in our country. Hence we took the study to see the trends of animal bite.

\section{Patient and method:}

This observational study was done in Infectious Disease Hospital and emergency department of Sir Salimullah Medical College and Mitford Hospital during $1^{\text {st }}$ to $27^{\text {th }}$ February, 2010. Total 235patients was selected withconvenient sampling method. Patients presenting with Category II and Category III of any age and both sex were included in the study. Data was collected and recorded in a predesigned case record form by face to face interview with patient and patient attendants. Everybody was given contact number and followed up over cell phone to know regarding completion of vaccine.The data was analyzed in Epi Info ${ }^{\mathrm{TM}} 6$ manually and results are described as percentage and number.

\section{Results:}

Total 232 patients attended at Infectious Disease Hospital and 3 patients attended emergency department of Sir Salimullah Medical College Mitford Hospital. Though age distribution was wide ranging from 3 year to 80 years, younger age group was affected mostly and $49.79 \%(n=117)$ of population was within 18 year group. Predominantly male was exposed, male female ratio was 4.87. Twenty one percent $(n=49)$ did not go to school and was illiterate, 48.94\% ( $\mathrm{n}=118)$ patients could complete primary education, $30.21 \%(n=71)$ had secondary education and beyond secondary school. 
Table-I

Table showing the demographic and socio-economic pattern of victims of animal bite.

\begin{tabular}{llc}
\hline \multicolumn{2}{c}{ Demographic and socio-economic pattern } \\
\hline Sex & Male & $195(82.98 \%)$ \\
& Female & $40(17.02 \%)$ \\
Age & $3-18$ years & $117(49.79 \%)$ \\
& $19-50$ & $99(42.12 \%)$ \\
& $51-80$ & $19(8.09 \%)$ \\
Settings & Urban & $120(51.06 \%)$ \\
& Rural & $115(48.94 \%)$ \\
Education & Illiterate & $49(20.85 \%)$ \\
& Primary & $115(48.94 \%)$ \\
& Second and above & $71(30.21 \%)$ \\
& $<3,000$ & $70(29.79 \%)$ \\
Monthly income & $3,000-5,0000$ & $129(54.89 \%)$ \\
& $5,000-10,000$ & $20(8.51 \%)$ \\
& $>10,000$ & $16(6.84 \%)$ \\
\hline
\end{tabular}

$60 \%(n=141)$ patient came from outside Dhaka city. Most of patient came from poor socio-economic condition. $29.79 \%(n=70)$ victims had monthly family income less than taka three thousand and 54.89\% $(\mathrm{n}=129)$ had family income taka three thousand to five thousand. Only $8.51 \%(n=20)$ and $6.84 \%(n=16)$ has family income within taka five thousand to ten thousand and more than taka ten thousand respectively. Patients presented equally from both urban (n=120)and rural( $\mathrm{n}=115)$.

\section{Details of exposure of animal:}

Ninety one present $(n=214)$ of bites was dog bite and rest was cat bite $(n=21)$ and most of animal was stray $\operatorname{dog}(94.89 \%)$. No animal was vaccinated previously against rabies. Nature of exposure was predominantly bite which was $83.82 \%(n=197)$ percent and scratch was $16.12 \%(n=38)$. Most bites were unprovoked and only 10 victims $(4.25 \%)$ present with provoked bite.

Most of bite was in lower limb71\% $(n=166)$ then upper limb 19\% $(n=45)$ and head neck region $6.80 \%(n=16)$. Only $3.42 \%(n=7)$ presented with bite in trunk and other site.Most of patient with the single bite $70.21 \%(\mathrm{n}=165)$ but multiple bite was not uncommon (two-22.12\%, n=52; three or more-7.77\%, n=18). Most of bite was category- III $(86.81 \%, n=204)$ and category II was only $13.19 \%$.There was no history of pre exposure vaccination.

\section{Table-II}

Table showing the details of exposure of animal bite.

\begin{tabular}{llc}
\hline \multicolumn{2}{c}{ Details of exposure of animal bite } \\
\hline Name of animal & Dog & $214(91.06 \%)$ \\
& Cat & $21(8.94 \%)$ \\
Nature of animal & Stray & $223(94.89 \%)$ \\
& Domestic & $12(5.11 \%)$ \\
& Wild & 0 \\
Nature of & Bite & $197(83.82 \%)$ \\
exposure & Scratch & $38(16.12 \%)$ \\
& Lick & 0 \\
Nature of bite & Provoked & $10(4.25 \%)$ \\
& Unprovoked & $225(95.75 \%)$ \\
Site of bite & Lower limb & $166(70.64 \%)$ \\
& Upper limb & $45(19.14 \%)$ \\
& Head neck & $16(6.80 \%)$ \\
Number of bite & Single & $7(3.42 \%)$ \\
& Two & $165(70.21 \%)$ \\
exposure & Three and more & $18(7.77 \%)$ \\
& Category II & $31(13.19 \%)$ \\
& Category III & $204(86.81 \%)$ \\
\hline
\end{tabular}

\section{Local wound care:}

Only $28.93 \%(n=68)$ victims washed the wound with water and soap and rest of victims $71.06 \%(n=167)$ did not washed the wound. Use of antiseptics like alcohol and or iodine was observed in $23.83 \%(n=56)$ of respondents. Only $8.08 \%(n=19)$ patients got antibiotics and rest $91.92 \%$ (167) of patients did not get any antibiotic, $5.96 \%(n=14)$ patients got their wounds closed with stitches and $6.38 \%(n=15)$ of patients were given tetanus prophylaxis.

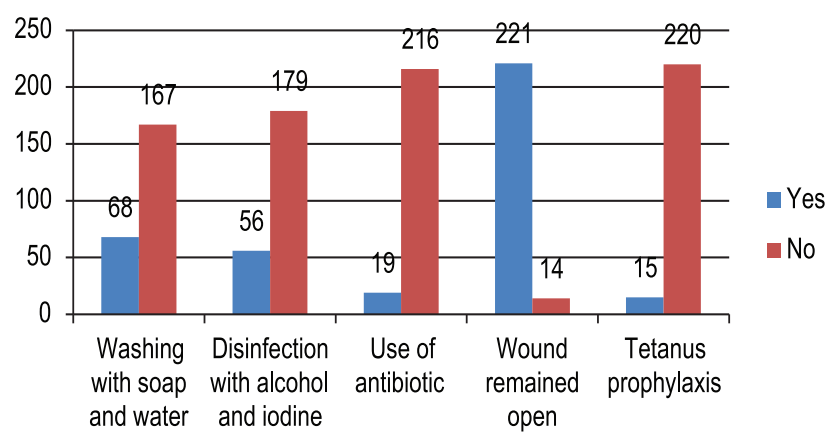

Fig.-1: Bar diagram showing frequency of washing with soap and water, disinfection with alcohol and iodine, use of antibiotic, wound remain open and tetanus prophylaxis. 


\section{Post exposure vaccination:}

One patient came after 2 hours and $5.10 \%(n=12)$ patients came within 12 hours $14.04 \%(n=33)$ and mean duration of bite and first dose vaccination is 75 hours (SD 8.9 Hours).

Nerve tissue vaccination was $81.70 \%(n=192)$ cell culture vaccine was $18.29 \%(n=43)$.

During follow up 20.85\% ( $\mathrm{n}=49)$ patient could not reached over cell phone and could not be known about their completion of vaccination and $62.98 \%(n=148)$ patient completed vaccination and $11.91 \%(n=28)$ patient could not completed their vaccination. Only $3.83 \%(n=9)$ patient got rabies immunoglobin which was equine. Over cell phone victims were on follow up for three month and only $52.34 \%(n=123)$ could contacted till end and any victim developed neither severe adverse reaction (e.g. Transvers myelitis, Encephalitis) nor rabies.

\section{Discussion}

Over 5 years (January 2004-December 2008) a total of 150,068 patients attended at Infectious disease hospital ( IDH) for proper management and treatment of animal bites. On an average 29,888 (95\% confidence interval 24,729-35,046) patients attended per year ${ }^{12}$. As Institute of Public Health does not dispense nerve tissue vaccine without recommendation of IDH so people from various region who want to get nerve tissue vaccine has to come first at IDH.

Though animal bite is a medical urgency, 60\% of patient came for treatment from outside of Dhaka district. Therefore there is inevitable delay in getting start of treatment. Age distribution was wide but $49.79 \%$ of population was within age limit of 18 year. Hossain M. et. al. showed $31.5 \%$ of animal bite victims attending at IDH were under age of 10 years, $22.2 \%$ of that were between age of 11-20 and $19.2 \%$ were within 21 - 30 years. It reflects children and young adult are always mostly affected. There was male predominance among the victims which was $82.98 \%$. From 2004 - 2008 total 116,418 (77.6\%) victims were male and $33,608(22.4 \%)$ victims were female ${ }^{12}$. In India $72.4 \%$ animal bite victims were males and $47.5 \%$ were children in age group of $2-18$ years in a multicentre study. ${ }^{13}$

F Akteret. al found $87.1 \%$ of 101 patients presenting with rabies has history of dog bite ${ }^{14}$. In an epidemiological study, Dog bites cause maximum morbidity (92\%) in India; second most common biting animal is monkey $(3.2 \%)$, followed by cat $(1.8 \%)$, fox $(0.4 \%)$ etc. and bites are $64.3 \%$ of all exposure and unprovoked bites are $64.7 \%{ }^{13}$. In Bangladesh from
2004 - 2008 among 150,019 cases the species of animal that caused bite was recorded; dog bite was most frequent, found in 136,069 (90.7\%) cases followed by cat in 7495 (5.0\%), fox/jackal in 643 (0.4\%), mongoose in $426(0.3 \%)$ and undetermined in 5386 $(3.6 \%)$ cases $^{12}$. In this study $91.06 \%$ patient was bitten by dog and rest was by cat. Only $5.11 \%$ animal was of domestic, rest was stray dogs and $83.82 \%$ of nature of exposure was bite and rest was scratch and $95.75 \%$ bite was unprovoked. These are all associated with high risk for development of rabies. $70.21 \%$ of patients presented with the single bite but multiple bite was not uncommon (two-22.12\%, three or more- $7.77 \%)$. Most of bite was category- III (86.81\%) and category II was only $13.19 \%$.In this study proportion of category -III exposure was very high which indicates amount RIG would be required to treat the victims.

Over all wound management is frustrating in the study. Only about $28.93 \%$ of patient got their wound washed with water and soap, 23.83\% used alcohol or iodine for disinfection. In India before coming to antirabies center $58.5 \%$ people had washed the wound with water/soap or water alone ${ }^{13}$. It reflects that knowledge, attitude and practice of our poor and illiterate people regarding the issue which is not healthy and scientific at all. Use of antibiotic (8.08\%) and tetanus $(6.38 \%)$ prophylaxis is considerably low; it is important aspect of general management of any animal bite.

Majority of patients $(81.70 \%)$ in this series got nerve tissue vaccine. WHO supported the trend to abandon completely the production and use of brain-tissue including suckling mouse brain vaccines. Bangladeshwas producing inactivated sheep brain vaccine i.e. Nerve Tissue Vaccine (NTV) and consuming a large amount of this ineffective vaccine. So, the hardcore poor people failed to get that live saving treatment with post-exposure vaccination with modern cell culture vaccine. The study was done when the nerve tissue vaccine was in practice but government was planning to phase it out gradually. After gradual phase out of nerve tissue vaccine, now the Bnagladesh government is using modern cell culture vaccine throughout the country.

Essentially $86.81 \%$ of patient with category - III bite should have got rabies immunoglobin (RIG), only $3.83 \%$ patient received RIG. As most victims are poor and cannot afford cell culture vaccine and they also cannot afford high price of RIG. Not only in Bangladesh but also in India use of RIG is inadequate; only $2.1 \%$ of victims attending at animal bite center have RIG ${ }^{13}$. Lack of availability of RIG 
and improper knowledge regarding importance of use of RIG are important factors responsible for reduced use of RIG. No patient developed an adverse reaction of RIG in this study.As significant number victims $112(48 \%)$ could not contacted till the end of 3 months major complication of NTV and development of rabies could not be ascertained.

\section{Conclusion}

In this study a great proportion of poor people got nerve tissue vaccine due to lack of affordability. Local wound management was frustrating and RIG administration was negligible. Awareness regarding proper wound management is necessary and provision of vaccination and RIG should be at primary health care level to minimize delay of treatment of animal bite.

\section{References}

1. Report of a consultative meeting, World Health Organization, 10 January 2007.

2. MM Rahman, M Salimuzzaman, MB Alam, MA Rouf, MJ Hossain, MR Rahman. Human rabies in Bangladesh - a study of 684 cases. J Medicine 2007; 8:3-6.

3. Current WHO GUIDE for rabies pre and postexposure prophylaxis in Human. (WHO Department of food safety, zooneses and Food borne diseases.)

4. MR Amin, S Chowdhury, S Enam, S Rahman, AR Hossain, M Salimuzzaman, MA Kahhar. Two Cases of Dog Bite with Similar Clinical Presentation but Outcome Variation - A Case Report. J MEDICINE 2013; 14: 213-217

5. Rabies surveillance, communicable Disease Response (CSR) WHO, Geneva.
6. M Morgan,J Palmer. BMJ, 24 February 2007; Volume 334: pp413-417

7. Warell MJ, Riddell H, Yu LM, Phipps J, Diggle L, Bourhy $\mathrm{H}$ et al. A simplified 4- site economical intradermal post-exposure rabies vaccine regimen: a randomised controlled comparison with standard methods. PLoSNeg1 Trop Dis. 2008;2:e224.

8. http://www.dghs.gov.bd/licts_file/images/ Guideline/2010_National_Guideline_of_I D_PET_Final_Jun2010.pdf

9. MR Amin . National Guideline of rabies prophylaxis2010. J. Medicine 2011; 12:153-159

10. FRChowdhury, A Basher, MR. Amin, N Hassan and M I. Patwary. Rabies in South Asia: Fighting for Elimination.Recent Patents on Anti-Infective Drug Discovery, 2015; 10:30-34

11. R. Rashid, A.A. Sayeed A. Bashar M.R. Rahman, M.A.Faiz. Baseline Assessment of knowledge, Attitude and Practice of Population in a Rural Community in Bangladesh about Dog Bite and Treatment Seeking Behaviour. International Journal of Infectious Diseases, December, 2008; Volume 12, e441

12. Hossain M.et. al. Five - year (January 2004 December 2008) surveillance on animal bite and rabies vaccine utilization in the infectious disease hospital, Dhaka, Bangladesh. Vaccine 2011;29: 1036-1040.

13. Ichhpujani RL et. al. Epidemiology of animal bites and rabies cases in India. A multi centric study. J Commun Dis. 2008 Mar; 40(1):27-36

14. F Akter, MM Hoque, EU Ahmed, MA Faiz. Journal Chittagong MedicalCollege Teacher Association $2015 ; 26(1): 4-8$. 